\title{
Is external hydrocephalus a possible differential diagnosis when child abuse is suspected? Editorial
}

\author{
Nejat Akalan ${ }^{1}$ (D) \\ Received: 19 February 2021 / Accepted: 23 February 2021 / Published online: 12 November 2021 \\ (C) The Author(s), under exclusive licence to Springer-Verlag GmbH Austria, part of Springer Nature 2021
}

This is a retrospective review of 28 infants collected from two different countries and institutions whom their caregivers had been convicted of "child abuse." The purpose, descriptions, and the conclusion are well accepted but the article as a whole is rather confusing for the general neurosurgical community. The authors speculate that the terms, "benign enlargement of the subarachnoid spaces (BESS)" and subdural collections are sometimes misdiagnosed leading serious medico-legal problems. Subdural collections represent various conditions which are used interchangeably such as subdural hygroma, chronical subdural hematoma, and external hydrocephaly [1-3]. BESS and subdural collections have the common presentation, macrocephaly. Enlargement of subarachnoid spaces in infancy is the most common cause of macrocephaly and characterized clinically with large head circumference, normal or mildly motor and language delay, and increased cerebrospinal fluid (CSF) in the subarachnoid space [2]. Nevertheless, BESS has been commonly regarded as a reversible, self-limiting condition where infants presenting even with motor/ neurocognitive delay are reported to catch their peers by the age of 2 years [2-6]. On the other hand, subdural effusions definitely require trauma to develop. Fluid accumulation within the subdural space is either CSF penetrating through an arachnoidal tear following trauma or more likely acute subdural bleeding. Infants with macrocephaly due to chronic subdural collections are more likely to be chronically ill with failure to thrive and developmental delay, with full fontanelles and seizures on presentation $[1,3]$.

It has been speculated that children with BESS are to be predisposed to subdural hygromas; therefore, the authors

Nejat Akalan

nejata@tr.net

1 Medipol University, Istanbul, Turkey suggest that the presence of subdural hygromas should not necessarily suggest non-accidental injury. Nevertheless, BESS and concomitant subdural hematoma in an otherwise asymptomatic infant is rarely encountered and only few cases were reported [7-9]. The authors also question whether BESS is as benign as often described. The term BESS and subdural effusion of any type have been interchangeably used as similar entities in the article. Current radiological work-up, MR, and even cranial ultrasound can differentiate enlarged subarachnoid spaces from a subdural hygroma. MR or an ultrasound Doppler study can detect the cortical veins within enlarged subarachnoid spaces which is the hallmark of BESS. Subdural collections typically do not manifest any veins due to the compression of the sub-arachnoid spaces and the veins [2]. Contemporary information based on accumulated data, there should be a very little concern in differentiating a benign condition BESS from subdural collection of traumatic origin suggestive for child abuse. Contrary to the statement of the authors that "the presence of subdural hygromas should not necessarily suggest non-accidental injury," all cases presented except for two have clinical signs other than macrocephaly and subdural collections with signals other than CSF. Clinical and radiological data presented should be regarded as a separate entity than benign subarachoidal collections. As far as minor trauma cannot be disregarded in subdural effusions, it is not so controversial to be suspicious about shaken baby syndrome.

From the neurosurgical point of view, expert opinion should address whether a probability of trauma exists with the given radiological and clinical data. Further judgment for child abuse should include close collaboration of pediatricians, neurologists, psychiatrists, and finally forensic experts. Nevertheless, this article has a valuable hypothesis and messages but not convincing enough data to accept without objection. 


\section{References}

1. Tucker J, Choudhary AK, Piatt J (2016) Macrocephaly in infancy: benign enlargement of the subarachnoid spaces and subdural collections. J Neurosurg Pediatr. 18(1):16-20

2. Kuruvilla LC (2014) Benign enlargement of sub-arachnoid spaces in infancy. J Pediatr Neurosci 9:129-131

3. Khosroshahi N, Nikkhah A (2018) Benign enlargement of subarachnoid space in infancy: "a review with emphasis on diagnostic workup". Iran J Child Neurol. 12(4):7-15

4. Raul JS, Roth S, Ludes B, Willinger R (2008) Influence of the benign enlargement of the subarachnoid space on the bridging veins strain during a shaking event: a finite element study. Int J Legal Med. 122(4):337-340

5. Chazal J, Irthum B, Janny P (1989) Ventricular subarachnoidal hydrocephalus of arachnoid villi origin. Neurochirurgie 35(6):379-382
6. Yum SK, Im SA, Seo YM, Sung IK (2019) Enlarged subarachnoid space on cranial ultrasound in preterm infants: Neurodevelopmental implication. Sci Rep. 9(1):19072

7. Marino MA, Morabito R, Vinci S, Germanò A, Briguglio M, Alafaci C, Mormina E, Longo M, Granata F (2014) Benign external hydrocephalus in infants. A single centre experience and literature review. Neuroradiol J 27(2):245-250. https://doi.org/10.15274/NRJ-201410020

8. Ravid S, Maytal J (2003) External hydrocephalus: a probable cause for subdural hematoma in infancy. Pediatr Neurol. 28(2):139-141

9. Kapila A, Trice J, Spies WG, Siegel BA, Gado MH (1982) Enlarged cerebrospinal fluid spaces in infants with subdural hematomas. Radiology 142:669-672

Publisher's note Springer Nature remains neutral with regard to jurisdictional claims in published maps and institutional affiliations. 